Nqobile Ndlangamandla and Hadley S. Clayton*

\title{
The crystal structure of $2,2^{\prime}-\left(\left(1 E, 1^{\prime} E\right)-\right.$ (naphthalene-2,3 diylbis(azanylylidene)) bis(methanylylidene))bis(4-methylphenol), $\mathrm{C}_{26} \mathrm{H}_{22} \mathrm{~N}_{2} \mathrm{O}_{2}$
}

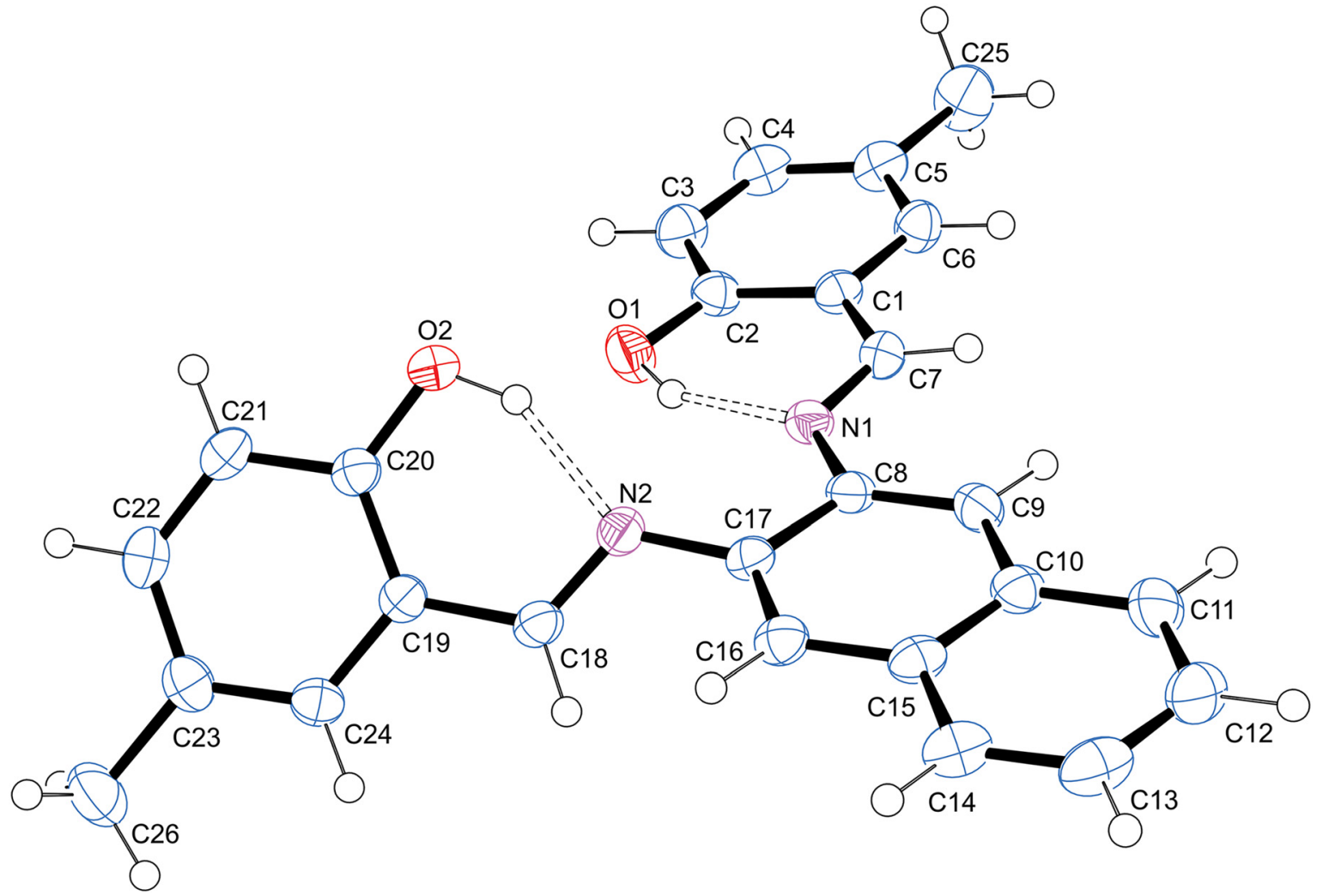

https://doi.org/10.1515/ncrs-2021-0385

Received October 5, 2021; accepted October 22, 2021; published online November 10, 2021

\section{Abstract}

$\mathrm{C}_{26} \mathrm{H}_{22} \mathrm{~N}_{2} \mathrm{O}_{2}$, monoclinic, $P 2_{1} / n$ (No. 14), $a=6.2362(2) \AA$, $b=16.3148(6) \AA, c=20.0521(7) \AA, \quad \beta=94.308(1)^{\circ}$, $V=2034.38(12) \AA^{3}, \quad Z=4, \quad R_{g t}(F)=0.0439$, $w R_{\text {ref }}\left(F^{2}\right)=0.1088, T=173 \mathrm{~K}$.

CCDC no.: 2107048

*Corresponding author: Hadley S. Clayton, Chemistry Department, University of South Africa, Unisa Science Campus, Johannesburg, South Africa, E-mail: clayths@unisa.ac.za. https://orcid.org/00000001-5472-853X

Nqobile Ndlangamandla, Chemistry Department, University of South Africa, Unisa Science Campus, Johannesburg, South Africa
The asymmetric unit of the molecular structure is shown in the figure. Table 1 contains crystallographic data and Table 2 contains the list of the atoms including atomic coordinates and displacement parameters.

Table 1: Data collection and handling.

\begin{tabular}{ll}
\hline Crystal: & Prism, red \\
Size: & $0.43 \times 0.23 \times 0.18 \mathrm{~mm}$ \\
Wavelength: & Mo $K \alpha$ radiation $(0.71073 \AA)$ \\
$\mu:$ & $0.08 \mathrm{~mm}^{-1}$ \\
Diffractometer, scan mode: & Bruker D8 Venture Photon, $\omega$-scans \\
$\theta_{\text {max }}$, completeness: & $27^{\circ},>99 \%$ \\
$N(h k l)_{\text {measured }}, N(h k l)_{\text {unique }}, R_{\text {int }}:$ & $71,804,4400,0.026$ \\
Criterion for $I_{\text {obs }}, N(h k l)_{\text {gt }}:$ & $I_{\text {obs }}>2 \sigma\left(I_{\text {obs }}\right), 3997$ \\
$N(\text { param })_{\text {refined }}:$ & 281 \\
Programs: & Bruker programs [1], SHELX [2], \\
& Win GX [3], PLATON [4]
\end{tabular}


Table 2: Fractional atomic coordinates and isotropic or equivalent isotropic displacement parameters $\left(\AA^{2}\right)$.

\begin{tabular}{|c|c|c|c|c|}
\hline Atom & $x$ & $y$ & $z$ & $U_{\text {iso }}{ }^{*} / U_{\text {eq }}$ \\
\hline$C 1$ & 0.04502 (18) & $0.56701(7)$ & $0.84538(6)$ & $0.0267(2)$ \\
\hline $\mathrm{C} 2$ & $-0.02471(18)$ & $0.61515(7)$ & $0.78952(6)$ & $0.0290(2)$ \\
\hline $\mathrm{C} 3$ & $-0.2084(2)$ & $0.66347(8)$ & $0.79207(7)$ & $0.0360(3)$ \\
\hline H3 & -0.256288 & 0.696117 & 0.754641 & $0.043^{*}$ \\
\hline $\mathrm{C} 4$ & $-0.3210(2)$ & $0.66401(8)$ & $0.84886(7)$ & $0.0361(3)$ \\
\hline $\mathrm{H} 4$ & -0.446258 & 0.697021 & 0.849589 & $0.043^{*}$ \\
\hline $\mathrm{C} 5$ & $-0.2559(2)$ & $0.61750(8)$ & $0.90511(6)$ & $0.0349(3)$ \\
\hline C6 & -0.07337 (19) & $0.56957(8)$ & $0.90212(6)$ & $0.0326(3)$ \\
\hline H6 & -0.026736 & 0.537274 & 0.93988 & 0.039 * \\
\hline $\mathrm{C} 7$ & $0.23024(18)$ & $0.51351(7)$ & $0.84407(6)$ & $0.0279(2)$ \\
\hline $\mathrm{H} 7$ & 0.267685 & 0.479291 & 0.881473 & $0.033^{*}$ \\
\hline $\mathrm{C} 8$ & $0.52784(17)$ & $0.46098(7)$ & $0.79148(5)$ & $0.0252(2)$ \\
\hline C9 & 0.62047 (18) & $0.41645(7)$ & $0.84422(6)$ & $0.0304(2)$ \\
\hline H9 & 0.555625 & 0.416804 & 0.885606 & $0.037^{\star}$ \\
\hline C10 & $0.80979(18)$ & $0.37014(7)$ & $0.83849(6)$ & $0.0296(2)$ \\
\hline C11 & $0.9070(2)$ & $0.32391(8)$ & $0.89268(7)$ & $0.0394(3)$ \\
\hline $\mathrm{H} 11$ & 0.843501 & 0.323416 & 0.934281 & $0.047^{\star}$ \\
\hline C12 & $1.0910(2)$ & $0.28010(8)$ & $0.88566(8)$ & $0.0412(3)$ \\
\hline $\mathrm{H} 12$ & 1.153802 & 0.24937 & 0.922342 & 0.049 * \\
\hline C13 & $1.1878(2)$ & $0.28022(7)$ & $0.82457(7)$ & 0.0388 (3) \\
\hline H13 & & & 0.820161 & $0.047^{*}$ \\
\hline C14 & 1.09891 (19) & $0.32438(8)$ & $0.77141(7)$ & $0.0347(3)$ \\
\hline H14 & 854 & 4205 & 389 & $0.042^{*}$ \\
\hline C15 & $0.90793(17)$ & $0.37043(7)$ & $36(6)$ & $0.0277(2)$ \\
\hline C16 & $0.81133(18)$ & $0.41672(7)$ & $0.72296(6)$ & $0.0286(2)$ \\
\hline H16 & 0.8763 & 0.417534 & 0.681609 & $0.034^{*}$ \\
\hline C17 & 0.62594 (17) & $0.46044(7)$ & $3(5)$ & $0.0254(2)$ \\
\hline C18 & $0.62596(17)$ & $0.54356(7)$ & $0.63454(5)$ & $0.0268(2)$ \\
\hline H18 & 0.775122 & 0.552368 & 0.645323 & $0.032^{*}$ \\
\hline C19 & $0.52434(17)$ & 0.578 & $9(5)$ & $52(2)$ \\
\hline $\mathrm{C} 20$ & $0.30617(17)$ & $0.56363(7)$ & $8(5)$ & $0.0262(2)$ \\
\hline $\mathrm{C} 21$ & 0.21884 (19) & $0.59586(7)$ & $0.49300(6)$ & 0.0308 (3) \\
\hline $\mathrm{H} 21$ & 0.0726 & 0.585612 & 0.478716 & $0.037^{\star}$ \\
\hline $\mathrm{C} 22$ & $0.3443(2)$ & $0.64256(7)$ & $0.45392(6)$ & $0.0319(3)$ \\
\hline $\mathrm{H} 22$ & 0.281255 & 0.664899 & 0.41331 & $0.038^{*}$ \\
\hline $\mathrm{C} 23$ & $0.5612(2)$ & $0.65815(7)$ & $0.47200(6)$ & $0.0315(3)$ \\
\hline $\mathrm{C} 24$ & $0.64721(18)$ & $0.62542(7)$ & $0.53185(6)$ & $0.0294(2)$ \\
\hline H24 & 0.794305 & 0.635234 & 0.545277 & $0.035^{\star}$ \\
\hline $\mathrm{C} 25$ & $-0.3840(2)$ & $0.61715(11)$ & $0.96621(7)$ & 0.0518 (4) \\
\hline $\mathrm{H} 25 \mathrm{~A}$ & -0.328547 & 0.574343 & 0.997168 & $0.078^{\star}$ \\
\hline $\mathrm{H} 25 \mathrm{~B}$ & -0.535567 & 0.606249 & 0.952662 & $0.078^{*}$ \\
\hline $\mathrm{H} 25 \mathrm{C}$ & -0.370861 & 0.670625 & 0.9884 & $0.078^{\star}$ \\
\hline C26 & $0.6953(2)$ & $0.70756(10)$ & $0.42709(7)$ & $0.0471(3)$ \\
\hline $\mathrm{H} 26 \mathrm{~A}$ & 0.839967 & 0.71502 & 0.448897 & $0.071^{*}$ \\
\hline $\mathrm{H} 26 \mathrm{~B}$ & 0.628259 & 0.761238 & 0.418558 & $0.071^{*}$ \\
\hline $\mathrm{H} 26 \mathrm{C}$ & 0.704933 & 0.678529 & 0.384633 & $0.071^{*}$ \\
\hline N1 & $0.34438(15)$ & $0.51130(6)$ & $0.79374(5)$ & $0.0271(2)$ \\
\hline $\mathrm{N} 2$ & $0.51790(15)$ & $0.50122(6)$ & $0.67432(5)$ & $0.0272(2)$ \\
\hline 01 & 0.07909 (15) & $0.61439(6)$ & $0.73288(5)$ & $0.0394(2)$ \\
\hline 02 & $0.17886(13)$ & $0.51870(6)$ & $0.59130(4)$ & $0.0337(2)$ \\
\hline $\mathrm{H} 1$ & 0.199 (3) & $0.5790(13)$ & $0.7413(10)$ & $0.073(6)^{\star}$ \\
\hline $\mathrm{H} 2$ & $0.266(3)$ & $0.5026(12)$ & $0.6290(10)$ & $0.065(5)^{\star}$ \\
\hline
\end{tabular}

\section{Source of materials}

All reagents are commercially available and were used without further purification. The Schiff base compound was prepared by the condensation reaction of 2,3-diaminonaphthalene $0.356 \mathrm{~g}(0.22 \mathrm{mmol})$ and 2-hydroxy-5-methylbenzaldehyde $0.598(0.44 \mathrm{mmol})$ in $10 \mathrm{ml}$ dry methanol. The reaction mixture was heated under microwave irradiation $\left(100^{\circ} \mathrm{C}, 100 \mathrm{~W}\right)$ for $10 \mathrm{~min}$. On cooling to room temperature an orange powder precipitated out of the reaction mixture. The solid obtained was filtered and washed with methanol to give the target product in $97 \%$ yield. Crystals of the title compound were obtained as deep orange needles by slow evaporation of an ethanol solution at room temperature over a period of five days.

\section{Experimental details}

Intensity data was determined on a Bruker Venture D8 Photon CMOS diffractometer with graphite-monochromated Mo $K_{\alpha 1}(\lambda=0.71073 \AA)$ radiation at $173 \mathrm{~K}$ using an Oxford Cryostream 600 cooler. Data reduction was carried out using the program SAINT+, version 6.02 [1] and empirical absorption corrections were made using SADABS [1]. The structure was solved in the WinGX [2] Suite of programs, using intrinsic phasing through SHELXT [3] and refined using SHELXL-2017 [3]. All C bound hydrogen atoms were placed at idealized positions and refined as riding atoms with isotropic parameters 1.2 times or 1.5 times those of their parent atoms. O-bound hydrogen atoms were located in the difference Fourier map and their coordinates and isotropic displacement parameters refined freely. Diagrams and publication material were generated using ORTEP-3 [2], and PLATON [4].

\section{Discussion}

Salen-type ligands are a class of Schiff base compounds with nitrogen and oxygen donor atoms. These tetradentate ligands have received much attention due to their versatility and rich coordination chemistry [5-7]. The modularity of synthesis of these ligands allows for the selective modification of the steric and electronic properties by alteration of the diamine or salicylaldehyde moieties. The salen compounds have potential application in inorganic 
biochemistry, catalysis, magnetism and medical imaging $[8,9]$. When coordinated to transition metal ions; the complexes exhibit a broad range of biological activities including antifungal, antibacterial, antimalarial, antiproliferative and antiviral properties [5-8]. As a part of our current research focus on Schiff base compounds as ligands, we herein report the molecular structure of a new naphthalene functionalized salen-type ligand.

The title compound crystallizes in the monoclinic space group $P 2_{1} / n$ (no. 14), with four molecules per unit cell. The bond lengths and angles are within the expected ranges and are comparable to related structures $[10,11]$. As expected, selected carbon-carbon bond lengths within the aromatic naphthalene rings are shorter than typical aromatic double bonds, showing bond localization. The C8-C9, C16-C17, C11-C12 and C13-C14 bonds have values of 1.374, 1.372, 1.368 and $1.369 \AA$ respectively which is ascribed to the Mills-Nixon effect which accounts for bond lengths changes during benzene ring annulation [12].

The molecule is non-planar, because there is a torsional twist observed about the naphthalene ring, with a (N1-C8C17-N2) dihedral angle of $-7.52^{\circ}$. While it is observed that the polyaromatic naphthalene ring is almost coplanar with one of the phenol rings of the molecule, the second phenol ring is rotated about the $\mathrm{N} 2-\mathrm{C} 17$ bond by $c a$. $27^{\circ}$. The conformation adopted may be due to steric and electronic effects experienced by the phenolic hydroxyl and imine groups of the molecule [13].

In the crystal, hydrogen bonds supported by the amine group can be observed. There are two strong intramolecular hydrogen bonds between the hydroxyl group and nitrogen atom of this compound, with $\mathrm{O} 1-\mathrm{H} 1 \cdots \mathrm{N} 1$ at 2.5984(13) $\AA$ and O2-H2 $\cdots \mathrm{N} 2$ at 2.6065(13) A. In addition, $\pi$-stacking is a prominent feature in the crystal structure of the compound. There is intermolecular aromatic $\pi-\pi$ - interactions observed between the out-of-plane phenol rings.

Acknowledgments: The authors would like to thank Professor A. Lemmerer (University of the Witwatersrand) for his assistance with crystallographic data collection.

Author contributions: All the authors have accepted responsibility for the entire content of this submitted manuscript and approved submission.
Research funding: None declared.

Conflict of interest statement: The authors declare no conflicts of interest regarding this article.

\section{References}

1. Bruker. SAINT-Plus and SADABS; Bruker AXS Inc.: Madison, Wisconsin, USA, 2004.

2. Sheldrick G. M. A short history of SHELX. Acta Crystallogr. 2008, A64, 112-122.

3. Farrugia L. J. WinGX suite for small-molecule single-crystal crystallography. J. Appl. Crystallogr. 1999, 32, 837-838.

4. Spek A. L. Structure validation in chemical crystallography. Acta Crystallogr. 2009, D65, 148-155.

5. Nworie F. S. Bis(salicylidene), ethylenediamine(salen) and bis(salicylidene) ethylenediamine-metal complexes: from structure to biological activity. J. Anal. Pharm. Res. 2016, 3, 1-10.

6. Cozzi P. G. Metal-salen Schiff base complexes in catalysis: practical aspects. Chem. Soc. Rev. 2004, 33, 410-421.

7. Leoni L., Dalla Cort A. The supramolecular attitude of metal-salophen and metal-salen complexes. Inorganics 2018, $6,42$.

8. Azam M., Hussain Z., Warad I., Al-Resayes S. I., Khan M. S., Shakir M., Kruszynski R. Novel Pd(II)-salen complexes showing high in vitro anti-proliferative effects against human hepatoma cancer by modulating specific regulatory genes. Dalton Trans. 2012, 41, 10854-10864.

9. Kocyigit O. Properties and synthesis of the $\mathrm{Cr}$ (III)-salen/salophen complexes containing triphenylamine core. Synth. React. Inorg. Metal-Org. Nano-Metal Chem. 2012, 42, 196-204.

10. Mohamed E. M., Muralidharan S., Panchanatheswaran K., Ramesh R., Low J. N., Glidewell C. 6,6'-Dimethoxy-2,2'-[(1R,2R)cyclohexane-1,2-diylbis(nitrilomethylidyne)] diphenol: three $\mathrm{C}-\mathrm{H} \cdots \mathrm{O}$ hydrogen bonds generate a three-dimensional framework. Acta Crystallogr. C 2003, 59, 367-369.

11. Chandini K. M., Fares H. A., Eman E. S., Nuha Y. E., Hela F., Sridhar M. A., Lokanath N. K. Synthesis, crystal structure, Hirshfeld surface analysis, DFT calculations, 3D energy frameworks studies of Schiff base derivative $2,2^{\prime}$-((1Z,1')(1,2-phenylene bis(azanylylidene)) bis(methanylylidene)) diphenol. J. Mol. Struct. 2021, 1244, 130910.

12. Stanger A. Is the Mills-Nixon effect real? J. Am. Chem. Soc. 1991, 113, 8277-8280.

13. Kargar H., Torabi V., Akbari A., Behjatmanesh-Ardakani R., Sahraei A., Tahir M. N. Synthesis, crystal structure, spectroscopic investigations, and computational studies of $\mathrm{Ni}$ (II) and $\mathrm{Pd}$ (II) complexes with asymmetric tetradentate NOON Schiff base ligand. Struct. Chem. 2019, 30, 2289-2299. 